\title{
Mostra de Ciência: Um Evento de Extensão da UFPR
}

\author{
Maria Aparecida Biason Gomes ${ }^{1}$ \\ Liliana Micaroni ${ }^{2}$ \\ Regina Maria Queiroz de Mello ${ }^{3}$ \\ José Luís Guimarães ${ }^{4}$
}

Feira ou Mostra de Ciências é uma oportunidade para o desenvolvimento da cultura científica. O evento de extensão da Universidade Federal do Paraná "Mostra de Ciência" é uma divulgação das atividades de extensão realizadas na UFPR envolvendo o Setor de Ciências Exatas e o Setor de Educação Profissional e Tecnológica (SEPT). Neste trabalho relatamos as atividades relacionadas com a área de química: experimentos em química e jogos educativos que ocorreram na primeira e segunda edição deste evento. Os experimentos em química foram expostos por estudantes do ensino médio, que participaram do projeto de extensão "Pensando e Fazendo Ciência" do Departamento de Química da UFPR. Os jogos educativos em química foram executados por estudantes do ensino médio do SEPT/UFPR. A preparação e execução desse evento contou com a participação ativa dos estudantes de ensino médio, dos bolsistas de extensão e dos professores. Foram aplicados questionários impessoais aos visitantes e aos estudantes expositores em que se observa uma avaliação positiva em duas edições do evento. Portanto, a Mostra de Ciência foi um evento de extensão que promoveu o desenvolvimento da cultura científica entre estudantes do ensino médio, despertando o seu interesse pela ciência e possibilitou aos bolsistas uma experiência na área de ensino de química, além de desenvolver habilidades em laboratório e em pesquisa. Ainda, a participação em jogos educativos em química propiciou aos visitantes (estudantes de ensino médio) o desenvolvimento do pensamento científico e reforço de conceitos básicos em química.

Palavras-chave: Mostra de Ciência, Experimentos em química, Jogos educativos.

\section{Science Exhibition: A Ufpr Extension Event}

Science exhibitions are an opportunity for scientific culture development. The extension event "Science Exhibition" at the Federal University of Parana is a divulgation of the extension activities taken place at UFPR that involves the Exact Sciences Department and the Department of Professional and Technological Education (SEPT). In this work, we report the activities related to the Chemistry field: chemistry experiments and educational games that took place in the first and second editions of this event. The chemistry experiments were presented by high school students who participated in the extension project "Thinking and Doing Science" by the UFPR Chemistry Department. The educational games in chemistry were performed by high school students from the SEPT/UFPR. This event preparation and execution relied on the active participation of the high school students, the extension interns and professors. Impersonal questionnaires were applied to visitors and to the exhibitor students, in which a positive evaluation of the event is observed in both editions of the event. Therefore, the Science Exhibition was an extension event that allowed the development of scientific culture among high school students, arousing their interest in science and provided the interns with experience in chemistry teaching, besides developing laboratory and research skills. Moreover, the participation in chemistry educational games offered the visitors (high school students) the opportunity for development of scientific thinking and improvement of basic concepts in chemistry.

Key words: Science Exhibition. Chemistry Experiments. Educational games.

\footnotetext{
1 Departamento de Química - UFPR - Projeto Pensando e Fazendo Ciência

${ }^{2}$ Universidade Federal do Paraná Departamento de Química

${ }^{3}$ Universidade Federal do Paraná Departamento de Química

${ }^{4}$ Universidade Federal do Paraná Setor de Educação Profissional e Tecnológica
} 


\section{Introdução}

As Feiras de Ciências ou Mostras de Ciências são conhecidas como uma atividade para a melhoria dos ensinos fundamental, médio e técnico das escolas, podendo despertar a vocação científica e incentivar novos talentos entre estudantes, através de sua participação em atividades de pesquisa científica e tecnológica. Essa atividade de ensino baseada no método de Iniciação Científica em Pesquisa é um procedimento pedagógico que leva ao aprendizado através da descoberta individual e estímulo à criatividade, propiciando a integração da comunidade que interage no processo. (PEREIRA, 2000)

Nesta ótica, a década de 60 foi um marco com as primeiras realizações de Feiras de Ciências, que se seguiram nas décadas posteriores com o acréscimo de outras atividades voltadas à divulgação da produção científica de estudantes. Em 2005, houve a criação do Programa Nacional de Apoio às Feiras de Ciências da Educação Básica -Fenaceb, pelo Ministério da Educação. (BRASIL, 2006)

Alguns benefícios provocados pelas Feiras de Ciências foram observados, tais como: crescimento pessoal, ampliação do conhecimento e comunicação, mudanças de hábitos e atitudes, criticidade, estímulo, motivação, criatividade e politização. (BRASIL, 2006)

A realização de projetos que envolvem pesquisas científicas pelos estudantes de ensino básico, para apresentação em Feiras de Ciências, tem se mostrado uma importante metodologia no desenvolvimento de novas competências nos estudantes, ao mesmo tempo em que a realização destas feiras cria um importante espaço de desenvolvimento da cultura científica. (SANTOS, 2012)

As Mostras ou Feiras de Ciências têm sido analisadas em diferentes aspectos em relação à importância da elaboração e participação em Feiras de Ciências: para a formação inicial dos futuros professores (DORNFELD; MALTONI, 2011) e (DE CASTRO et.al., 2012) e para a formação dos alunos do ensino médio e dos cursos técnicos (DE PAIVA MOTA et. al., 2012). Uma das funções da Feira é aproximar o estudante dos conteúdos de Ciências, através da experimentação, despertando o seu interesse pelas disciplinas na área de ciências. Esse foi o intuito da Feira de Ciências realizada no CEEP de Itabuna/BA em 2010, com as atividades de incentivo à pesquisa científica e a noção crítica dos alunos (DE PAIVA MOTA et. al., 2012). Os dados da pesquisa realizada por Hartmann e Zimmermann (2009) mostraram que as produções realizadas por estudantes do ensino médio de escolas públicas em Feira de Ciências são contextualizadas, mas a interdisciplinaridade é realizada pelos alunos e não pelos professores.

Revista Extensão em Foco, nº 13, Jan/ Jul (2017) p. 121 - 134. 
A Extensão Universitária, por ser um processo acadêmico vinculado à formação do cidadão, à produção e ao intercâmbio de conhecimentos que visem à transformação social, articulando-se com ensino e pesquisa, alinha-se com os objetivos de eventos desta natureza, pois além de trazer a academia para espaços da comunidade, serve também para estimular estudantes, hoje no ensino básico, para futuras carreiras universitárias. (SANTOS, 2012)

O evento de extensão universitária da Universidade Federal do Paraná (UFPR) "Mostra de Ciência", realizado em 2014 e 2015, foi uma das atividades propostas no Subprojeto de Extensão "Pensando e Fazendo Ciência" que faz parte do projeto "Ações em comum na UFPR: unindo novos talentos para a inclusão social e desenvolvimento da cultura científica" (CAPES-EDITAL $n^{\circ}$ 055/2012). Quatro atividades compõem este evento: experimentos de química, jogos educativos em química, experimentos em física e sessões de planetário. Este evento envolve os Departamentos de Química e de Física e o Setor de Educação Profissional e Tecnológica da UFPR. Neste trabalho serão relatadas as experiências relacionadas às atividades de química.

A atividade relacionada à exposição de experimentos em química envolve a atuação de estudantes de ensino médio que participaram de cursos de extensão vinculado ao projeto "Pensando e fazendo Ciência". Na atividade dos jogos educativos em química, procurou-se oportunizar e incentivar os visitantes deste evento a realizarem de forma lúdica e educativa a aplicação dos conhecimentos adquiridos durante o ensino médio sobre a tabela periódica (jogo da memória e dominó químico) e também sobre os cátions e ânions, para formarem substâncias inorgânicas (jogo das combinações). No trabalho de Cunha (CUNHA,2014) relata-se que os jogos são indicados e podem ser utilizados em momentos distintos e ilustra aspectos relevantes dos conteúdos trabalhados em sala pelos educadores da área da química, ou ainda podem servir como revisão ou síntese de conceitos desenvolvidos.

Essas duas atividades, exposição dos experimentos em química e jogos educativos em química, realizadas durante as duas edições do evento "Mostra de Ciência" serão objeto de análise neste relato de experiência.

O objetivo desse trabalho é analisar se este tipo de evento de extensão desperta o interesse de estudantes do ensino médio para a ciência, possibilitando o desenvolvimento da cultura científica e a geração de novos talentos. 


\section{Materiais e Métodos}

A primeira edição do evento (I Mostra de Ciência) ocorreu em 2014, com duração de 3 dias. A segunda edição (II Mostra de Ciência) ocorreu em 2015 com duração de quatro dias.

\section{Exposição dos Experimentos em Química}

Os experimentos em química foram expostos por estudantes do ensino médio e/ou técnico integrado que participaram do projeto "Pensando e Fazendo Ciência". Os estudantes tiveram uma vivência em pesquisa científica e execução de experimento na universidade, durante um mês, totalizando 80 horas de atividade.

Um total de 60 estudantes da rede pública, vindos dos Colégios Estaduais Prof. Elysio Vianna, Paulo Leminski e São Paulo Apóstolo, do Centro Estadual de Educação Profissional de Curitiba e do Setor de Educação Profissional e Tecnológica da UFPR participaram das Mostras de Ciência como expositores dos experimentos em química. Durante os dias de realização do evento os estudantes se revezaram para explicar aos visitantes os experimentos expostos.

A divulgação dos experimentos na área de Química durante as duas Mostras de Ciência foi realizada em estandes. Cada estande continha um painel de 90 x $100 \mathrm{~cm}$, com informações sobre o experimento, e o material básico necessário para o entendimento e explicação do experimento em cada etapa de desenvolvimento deste.

Os temas dos experimentos expostos nos estandes foram: biodiesel, tratamento de resíduos, reciclagem, indicadores naturais de $\mathrm{pH}$, corantes naturais, óleos essenciais e plantas medicinais. Todas as atividades foram realizadas em equipe pelos estudantes do ensino médio, como a confecção dos painéis, a preparação dos estandes e a execução dos experimentos. O monitoramento, apoio e logística foi feito pela equipe de bolsistas de extensão e de professores.

\section{Jogos Educativos em Química}

Os jogos em química foram realizados na forma experimental e descontraídos através de disputas de gincanas entre duplas de estudantes visitantes do evento que foram formadas e inscritas no local. Em cada período (manhã e tarde) era disputada uma gincana, totalizando 
seis gincanas durante o evento. Aproximadamente 420 (2014) e 1060 (2015) visitantes, em cada um dos eventos, participaram dos jogos (vide Figura 1), da seguinte forma: i) etapa 1: 20 duplas jogaram o dominó químico e 20 duplas o jogo da memória, sendo classificadas 10 duplas como finalistas; ii) etapa 2: disputa de melhor dos jogos disputados na etapa 1 entre as duplas finalistas invertendo-se o jogo (as duplas vencedoras no dominó disputavam o jogo da memória) sendo classificadas 5 duplas semifinalistas; iii) etapa 3: disputa entre as 5 duplas no jogo das combinações (cátions e ânions), classificando-se as duplas de $1^{\text {o. }}$ ao $5^{\text {o. }}$ lugares. Para cada partida fez-se o registro dos ganhadores (conforme a Tabela 1). Nesta disputa cada dupla sorteava um cátion e um ânion, e a pontuação foi da seguinte forma: para acerto do nome do cátion (1 ponto), para acerto do ânion (1 ponto), para o acerto da fórmula molecular (2 pontos) e para o respectivo nome (3 pontos). A cada rodada era eliminada a dupla com menor pontuação até finalizar-se com uma dupla vencedora com maior pontuação.

As cinco (5) duplas que disputaram o jogo das combinações (os cátions e ânions) foram premiadas com brindes doados pela comunidade.

Figura 1: Fluxograma da dinâmica da seleção das duplas finalistas nos jogos educativos em química.

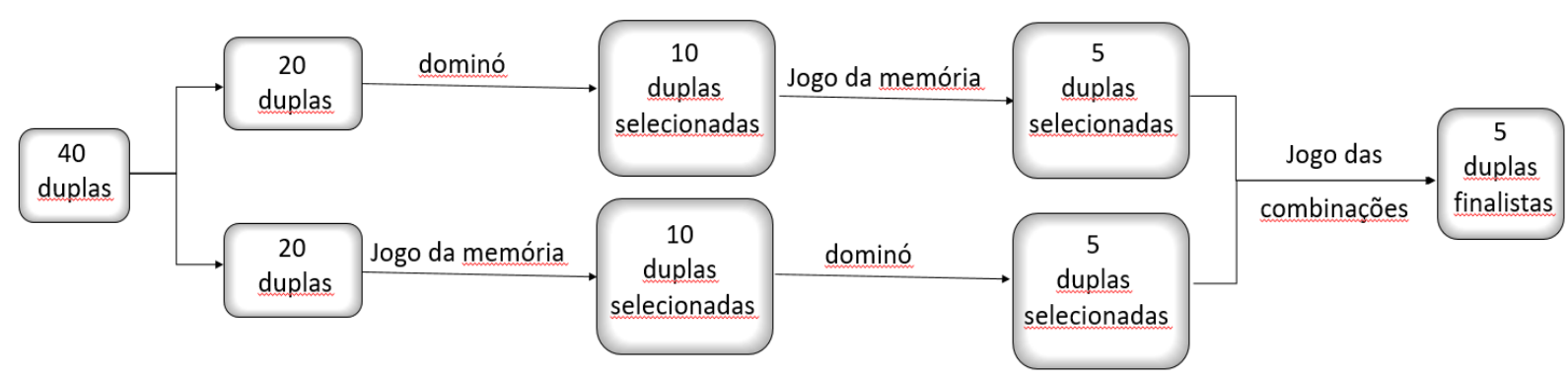

Tabela 1: Registro dos pontos para os jogos educativos.

\begin{tabular}{|l|c|c|c|}
\hline \multicolumn{4}{|c|}{ TABELA DE REGISTRO DE PONTOS } \\
\hline NOME DAS DUPLAS & PARTIDA 1 & PARTIDA 2 & PARTIDA 3 \\
\hline & & & \\
\hline
\end{tabular}

Revista Extensão em Foco, nº 13, Jan/ Jul (2017) p. 121 - 134. 


\section{Resultados e discussão}

As duas edições do evento de extensão "Mostra de Ciência" receberam mais de 6.000 visitantes. Esses visitantes eram, em sua maioria, estudantes do ensino médio, de escolas públicas e privadas do município de Curitiba/PR e região.

\section{Exposição dos Experimentos em Química}

Os estudantes de ensino médio e/ou técnico integrado tiveram participação efetiva na montagem do estande e explicação do experimento ao público visitante utilizando os conceitos científicos envolvidos nos mesmos.

A Figura 2 apresenta uma vista geral dos estandes com os visitantes durante a I Mostra de Ciência (Figura 2a) e a II Mostra de Ciência (Figura 2b).
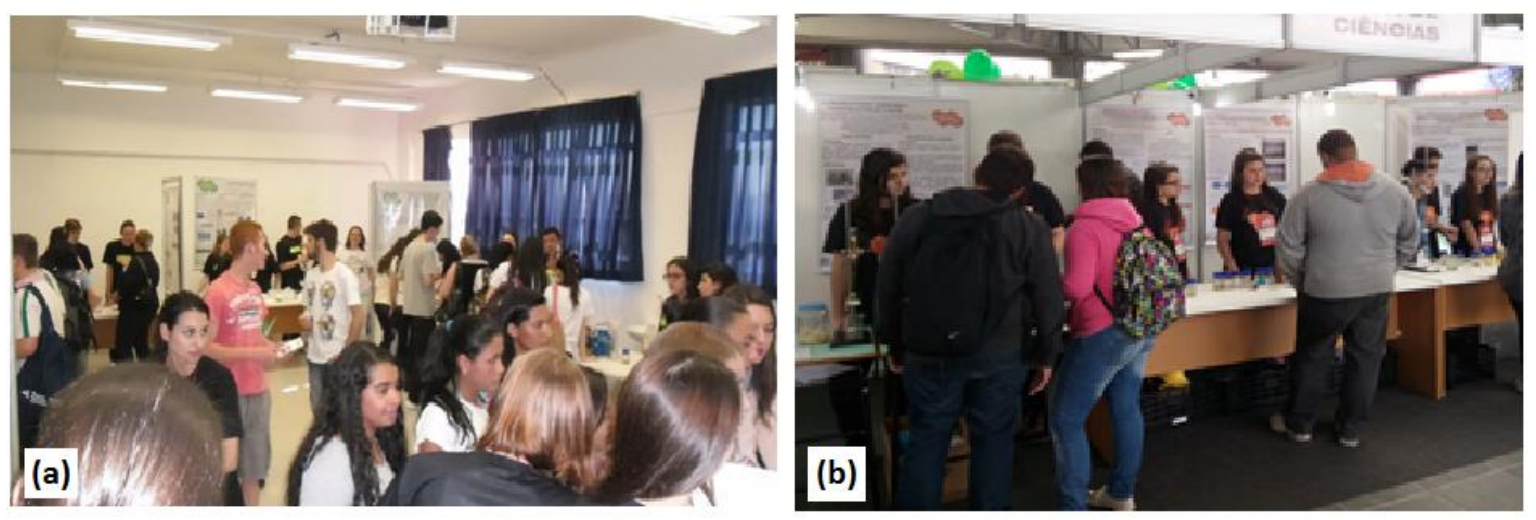

Figura 2: Espaço Físico utilizado na exposição dos experimentos em química durante o evento: (a) I Mostra de Ciência e (b) II Mostra de Ciência. Fonte: arquivos do projeto Pensando e Fazendo Ciência (PROEC 251/12).

Em cada um dos estandes, os estudantes do ensino médio puderam expor os experimentos de forma criativa e atrativa ao público visitante. Por exemplo, no estande do experimento "Extração de óleos essenciais", materiais tais como a matéria-prima (cascas de laranja), o equipamento da hidrodestilação em funcionamento, a utilização do óleo extraído em velas aromáticas e o pôster preparado pelos estudantes compunham este estande (Figura 3). 


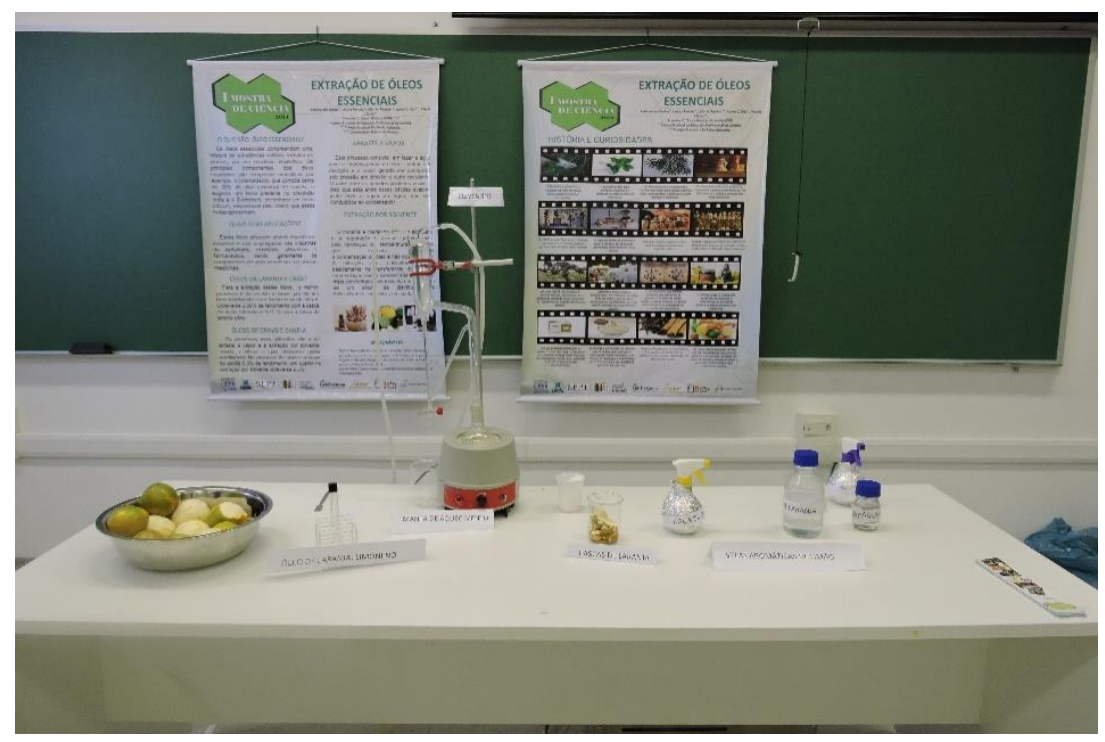

Figura 3: Estande do experimento do tema óleos essenciais. Fonte: arquivos do projeto Pensando e Fazendo Ciência (PROEC 251/12).

As Figuras 4a, 4b e 4c mostram, respectivamente, os estudantes expondo aos visitantes os experimentos sobre corantes naturais, síntese de biodiesel e tratamento de resíduos, respectivamente. A Figura $4 \mathrm{~d}$ mostra os visitantes participando de uma das atividades interativas como pintar, desenhar ou mesmo escrever uma mensagem com uma tinta preparada com um dos corantes extraídos do urucum.

Durante a explicação dos expositores, os visitantes faziam perguntas e questionamentos para um melhor entendimento dos experimentos expostos. Os estudantes demonstraram muita dedicação e empolgação durante a realização do evento, prendendo a atenção do público visitante. Isso foi confirmado pela aplicação de um questionário impessoal aos visitantes das Mostras.

Uma das perguntas respondidas pelos visitantes era sobre os temas dos experimentos apresentados nos estandes. Os visitantes responderam que gostaram mais do tema biodiesel, seguido dos óleos essenciais, dos indicadores naturais de $\mathrm{pH}$, reciclagem e corantes naturais, como se observa na Figura 5. 

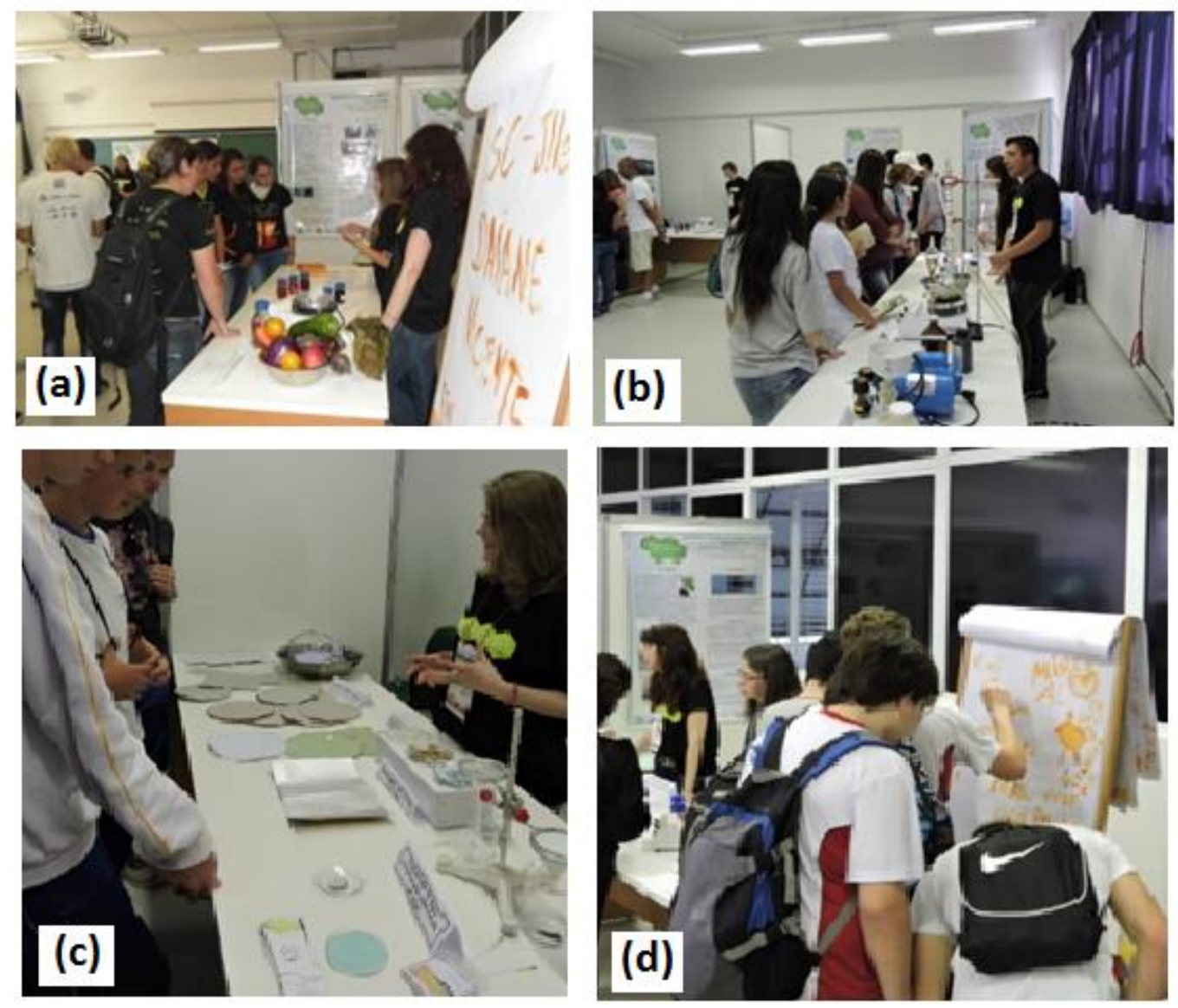

Figura 4: Estandes dos experimentos em química: (a) corantes naturais, (b) biodiesel (c) tratamento de resíduos e (d) atividade interativa com os visitantes: pintura usando tinta de urucum. Fonte: arquivos do projeto Pensando e Fazendo Ciência (PROEC 251/12).

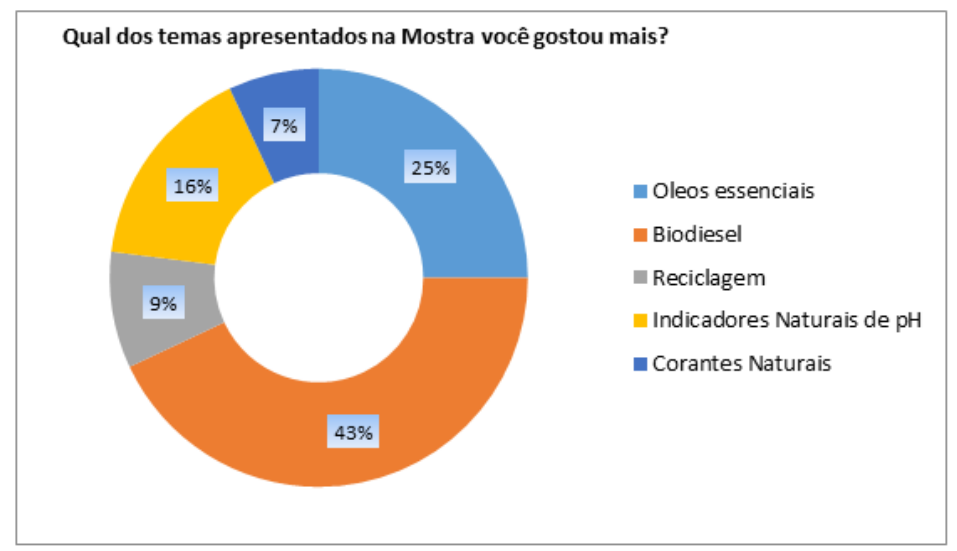

Figura 5: Resposta dos visitantes sobre os temas dos estandes. Fonte: elaborado pelos autores. 
Em outras duas perguntas os visitantes puderam classificar as suas respostas em quatro níveis (ótimo, bom, regular e ruim), Figura 6. Na questão de como avaliaram as explicações dos estudantes sobre os experimentos, 65\% consideraram ótimo e $30 \%$ bom. Percentagem semelhante foi avaliada sobre os temas dos experimentos apresentados.

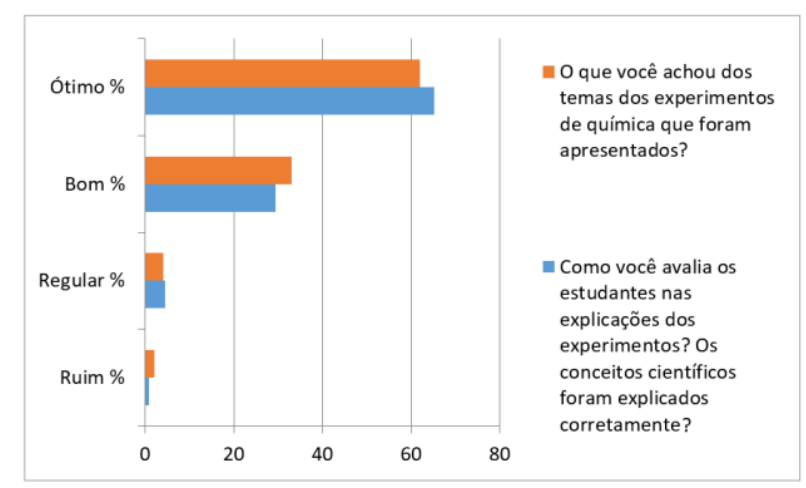

Figura 6: Resposta dos visitantes, classificadas em quatro níveis (ótimo a ruim), a duas perguntas. Fonte: elaborado pelos autores.

Outros questionamentos aos visitantes foram com repostas diretas (sim ou não), conforme Figura 7. Tem-se que 98\% visitariam a Mostra numa próxima oportunidade; 99\% indicariam esse evento a um amigo; $88 \%$ consideraram que os expositores incentivaram os visitantes a comparecerem no seu estande; $92 \%$ acharam que o evento contribuiu para a sua formação em química e $99 \%$ dos visitantes gostaram de como os experimentos foram expostos.

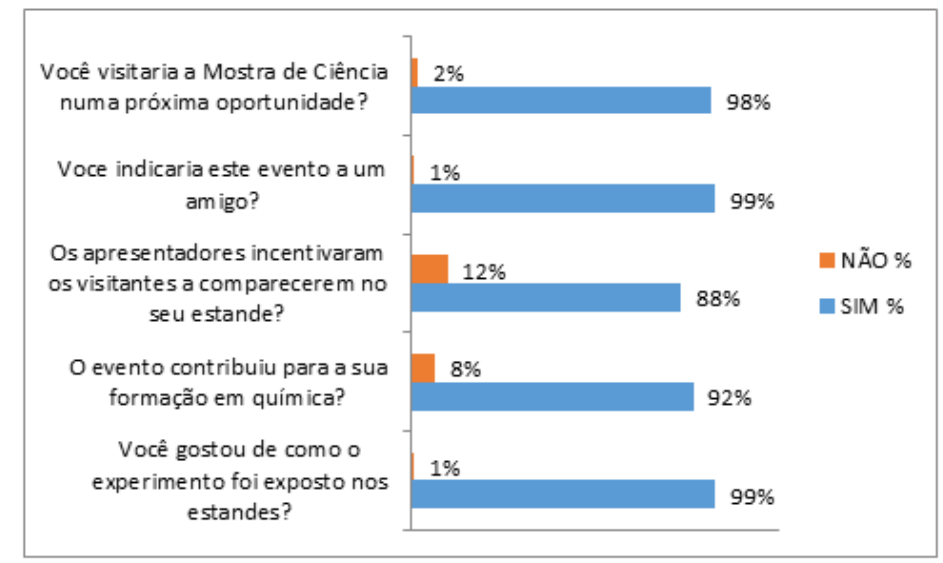

Figura 7: Resposta direta (sim ou não) dos visitantes a cinco perguntas. Fonte: elaborado pelos autores.

Revista Extensão em Foco, no 13, Jan/ Jul (2017) p. 121 - 134. 
Também foi aplicado um questionário impessoal aos estudantes expositores e foram obtidas respostas positivas em relação à sua participação no evento. Questões de relevância tais como: infraestrutura, preparação, e execução do evento e pós-evento, também foram avaliadas positivamente. No tópico execução do evento, Tabela 2, todos gostaram do assunto do trabalho que apresentaram; $86 \%$ dos apresentadores consideraram que incentivaram os visitantes a comparecerem no seu estande; sobre a explicação/exposição de seu trabalho, cerca de $58 \%$ consideraram que foi bom e cerca de $42 \%$ ótimo. Obtivemos unanimidade em que todos os estudantes participantes gostariam de apresentar outro experimento de química em outras oportunidades e indicariam o evento a um amigo.

Tabela 2: Respostas dos estudantes expositores

\begin{tabular}{|c|c|c|}
\hline Execução do Evento & $\begin{array}{c}\% \\
\text { SIM }\end{array}$ & NAO \\
\hline Você gostou do assunto do trabalho que apresentou? & 100 & 0 \\
\hline Como apresentador você incentivou os visitantes a comparecerem no seu \\
estande? & 86 & 14 \\
\hline Execução do Evento & Bom & Ótimo \\
\hline Como você avalia a explicação/exposição de seu trabalho para os visitantes? & 58 & 42 \\
\hline
\end{tabular}

Portanto, a avaliação da exposição dos experimentos em química durante as Mostras de Ciência foi positiva, pois os estudantes expositores se dedicaram à realização dos dois eventos e desenvolveram o interesse pela cultura científica. Esse evento de extensão é um incentivo à realização da pesquisa científica, através da busca de informações e experimentação. Além disso, a apresentação dos trabalhos contribui para a melhoria das interações sociais, comunicação e criatividade dos estudantes. Também, a avaliação foi positiva, concordando com a avaliação final feita por Santos (2012), no que diz respeito ao envolvimento das comunidades internas e externas a universidade, que corresponde ao principal papel de um projeto de extensão. 


\section{Jogos Educativos em Química}

O jogo de dominó químico tem por objetivo combinar as extremidades das peças do dominó de um mesmo elemento químico, sendo válida qualquer uma das três combinações possíveis: nomes do mesmo elemento químico, símbolos do mesmo elemento químico ou nome com símbolo do mesmo elemento químico. Uma partida de dominó está registrada na Figura 8a.

O jogo da memória tem por objetivo formar pares de cartas, sendo uma delas o símbolo de um elemento químico e a outra o seu respectivo nome. Na Figura $8 b$ podemos observar visitantes em um momento deste jogo.

O jogo das combinações tem por objetivo combinar as cartas sorteadas formando substâncias químicas pertencentes às funções inorgânicas (ácidos e bases de Arrhenius, óxidos, sais, hidretos e carbetos). São válidas uma das duas combinações possíveis: fórmulas moleculares, ou os nomes das substâncias químicas (oficial, comercial ou usual). O registro do momento em que uma dupla de visitantes está pensando na substância química capaz de ser formada pelo cátion e pelo ânion que eles sortearam está registrada na Figura 8c.

Aproximadamente 210 (2014) e 530 (2015) duplas de visitantes de cada um dos eventos participaram da atividade dos jogos em química. Todas as cinco duplas que participaram do jogo das combinações receberam premiação, classificadas do $1^{\circ}$ ao $5^{\circ}$ lugar. No total foram distribuídas 30 premiações de participação.

Com esta atividade com base na metodologia científica, procurou-se instigar os estudantes ao desenvolvimento do pensamento científico e o aprendizado de conceitos básicos necessários para maior fixação de conhecimentos, promovendo a disseminação do conhecimento.

A atividade lúdica tem por objetivo propiciar a construção do conhecimento cognitivo, físico, social e psicomotor o que o leva a memorizar mais facilmente o assunto abordado. Quando se cria ou se adapta um jogo ao conteúdo escolar, ocorre o desenvolvimento de habilidades que envolvem o indivíduo em todos os aspectos: cognitivos, emocionais e relacionais; e isto leva o estudante a se tornar mais competente na produção de respostas criativas e eficazes para solucionar os problemas.

A alegria em ver a participação dos visitantes nestes jogos e a seriedade que eles tiveram para ganhar as competições nos indica que os assuntos relacionados à química devem ser estimulados ao máximo para que o aprendizado ocorra de forma descontraída e interativa. 
A participação dos estudantes nos jogos permitiu a interação entre eles e, além de educativo, os jogos despertaram o prazer espontâneo, o desafio das vitórias pessoais e a interação de jovens de diferentes escolas e cidades que jamais se encontrariam.
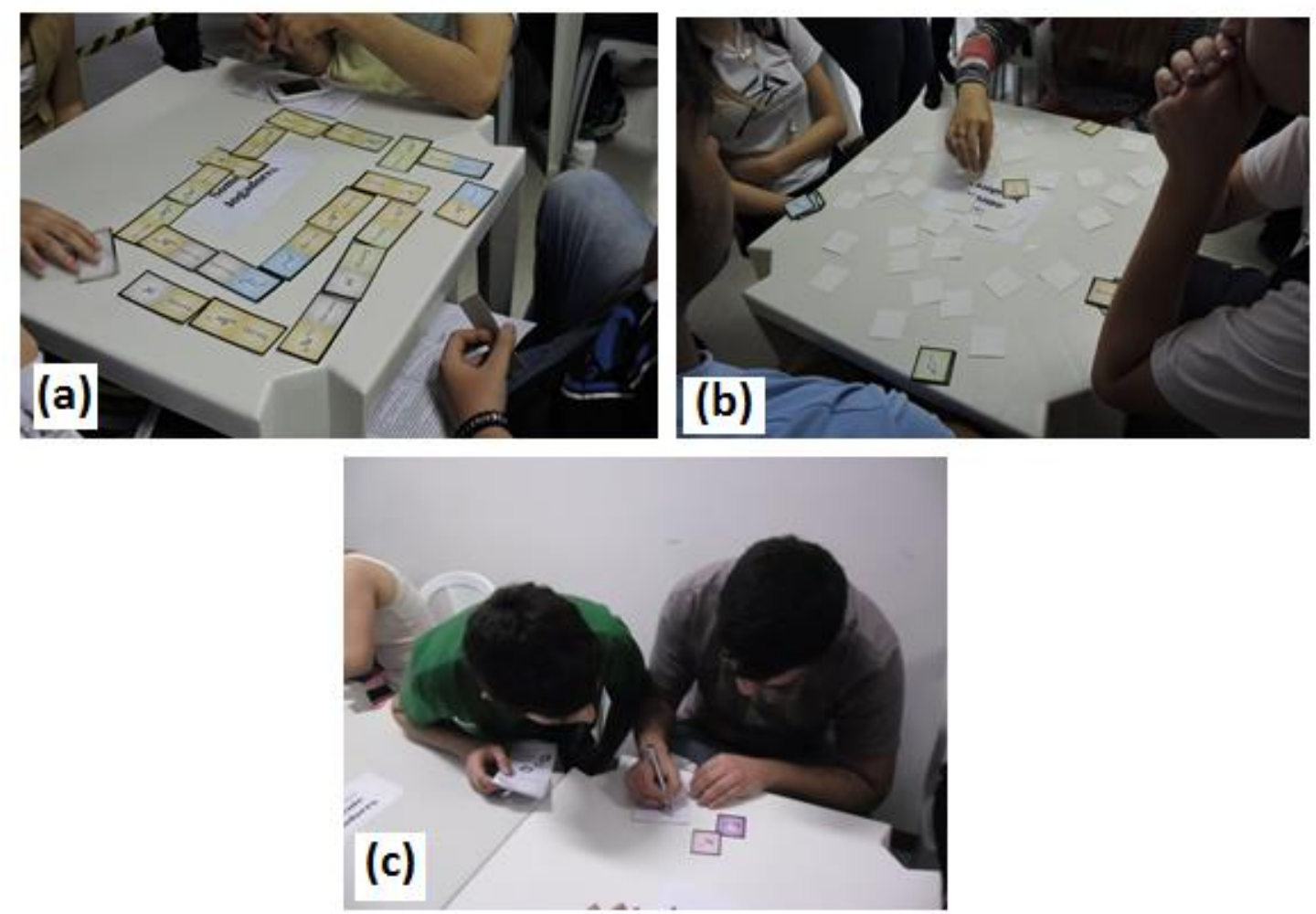

Figura 8: Atividades interativas com os visitantes, registradas durante o evento: (a) dominó químico (b) jogo da memória (c) jogo das combinações. Fonte: arquivos do projeto Pensando e Fazendo Ciência (PROEC 251/12).

\section{Conclusões}

Através da análise das duas edições do evento "Mostra de Ciência", conclui-se que este tipo de evento de extensão promove o desenvolvimento da cultura científica entre estudantes do ensino médio e é uma oportunidade para que esses estudantes se dediquem a um tema de interesse na área de química, com satisfação e entusiasmo, despertando o seu interesse pela ciência e incentivando a geração de novos talentos. Os bolsistas de extensão (alunos do Curso de Graduação em Química) ganham bastante experiência relacionada ao 
ensino da química além de desenvolver habilidades em laboratório e em pesquisa. A participação em jogos educativos em química propicia aos visitantes (estudantes de ensino médio) o desenvolvimento do pensamento científico e reforço de conceitos básicos em química.

\section{Agradecimentos}

Agradecemos à Universidade Federal do Paraná, à Capes (edital 055/2012), aos estudantes de graduação, bolsistas de extensão e voluntários: Cinthia T. R. Barbosa, Francine C. Claro, Ravena R. A. Maia, Stephanie A. Todesco, André L. S. W. Baptista, Ana C. de Oliveira, Lucas C. Gouveia, Murilo F. da Silva, Sara R. Gonçalves e, finalmente, a todos os estudantes de ensino médio que atuaram como expositores nestes eventos.

\section{Referências}

BRASIL - MINISTÉRIO DA EDUCAÇÃO. Secretaria de Educação Básica. Programa Nacional de Apoio às Feiras de Ciências da Educação Básica: Fenaceb. Brasília, DF, p. 11-26, 2006.

CUNHA, M. B. Jogos de Química: Desenvolvendo habilidades e socializando o grupo. In: ENCONTRO NACIONAL DE ENSINO DE QUÍMICA, Goiânia-GO, 2004. Anais, 028, 2004.

DE CASTRO, S.M.V. et al. Feira de Ciências: uma experiência interdisciplinar na formação de professores de ciências das séries iniciais do ensino fundamental. XVI ENCONTRO NACIONAL DE ENSINO DE QUÍMICA E X ENCONTRO DE EDUCAÇÃO QUÍMICA DA BAHIA, 2012, Salvador, BA. Disponível em <http://www.portalseer.ufba.br/index.php/anaiseneq2012/article/viewFile/7655/5443>.

Acesso em: 23 fev. 2015

DE PAIVA MOTA, C.C. et al. Feira de Ciências: atividade inovadora na formação docente? In: XVI ENCONTRO NACIONAL DE ENSINO DE QUÍMICA E X ENCONTRO DE EDUCAÇÃO QUÍMICA DA BAHIA, 2012, Salvador, BA. Disponível em: $<$ http://www.portalseer.ufba.br/index.php/anaiseneq2012/article/viewFile/7791/5521>.

Acesso em 24 fev. 2015;

DORNFELD, C.B.; MALTONI, K. L. A Feira de Ciências como auxílio para a formação inicial de professores de ciências e biologia. Revista Eletrônica de Educação. São Carlos, SP: UFSCar, v. 5, no. 2, p.42-58, nov. 2011. Disponível em 
〈http://www.reveduc.ufscar.br/index.php/reveduc/article/viewFile/200/120>. Acesso em 23 fev. 2015:

HARTMANN, A. M.; ZIMMERMANN, E. Feira de Ciências: a interdisciplinaridade e a contextualização em produções de estudantes do ensino médio. In: VII ENCONTRO NACIONAL DE PESQUISA EM EDUCAÇÃO EM CIÊNCIAS, 2009, Florianópolis, SC. Disponível em: 〈http://posgrad.fae.ufmg.br/posgrad/viienpec/pdfs/178.pdf>. Acesso em: 24 fev. 2015.

PEREIRA, A.B.; OAIGEN, E.R; HENNING, G.J.; Feiras de Ciências. Canoas, RS. Ed. ULBRA, 2000.

SANTOS., A. B. Feiras de Ciência: Um incentivo para desenvolvimento da cultura científica. Revista Ciência em Extensão. São Paulo, SP:UNESP, v.8, n.2, p.155-166, 2012. Disponível em: 〈http://ojs.unesp.br/index.php/revista_proex/article/view/717>. Acesso em: 20 fev 2015. 